\title{
Phytochemical Screening and Anti-diabetic Evaluation of Citrus sinensis Stem Bark Extracts
}

\author{
Azantsa Kingue Gabin Boris ${ }^{1,2^{*}}$, Djuikoo Nouteza Imelda ${ }^{1}$ \\ Kuikoua Tchetmi Wilfried ${ }^{2}$, Takuissu Guy ${ }^{1}$, Judith Laure Ngondi ${ }^{1}$ \\ and Julius Oben ${ }^{1}$ \\ ${ }^{1}$ Laboratory of Nutrition and Nutritional Biochemistry, Faculty of Science, University of Yaoundé 1, \\ P.O.Box: 812 Yaounde, Cameroon. \\ ${ }^{2}$ Department of Biochemistry and Molecular Biology, Faculty of Science, University of Buea, \\ P.O.Box: 63 Buea, Cameroon.
}

Authors' contributions

This work was carried out in collaboration between all authors. Authors AKGB and JO designed the study, performed the statistical analysis, wrote the protocol and wrote the first draft of the manuscript.

Authors DNI, TG and KTW managed the analyses of the study. Author JLN managed the literature searches. All authors read and approved the final manuscript.

Article Information

DOI: $10.9734 / I J B C R R / 2017 / 34051$

Editor(s):

(1) Mohamed Fawzy Ramadan Hassanien, Biochemistry Department, Zagazig University, Egypt.

Reviewers:

(1) Ramaiah Maddi, Hindu College of Pharmacy, India. (2) Keagile Bati, University of Botswana, Botswana. Complete Peer review History: http://www.sciencedomain.org/review-history/19271

Original Research Article

Received 11 ${ }^{\text {th }}$ May 2017

Accepted $23^{\text {rd }}$ May 2017

Published $31^{\text {st }}$ May 2017

\section{ABSTRACT}

Aim: Diabetes Mellitus remains amongst the highest cause of mortality in the world. This study was carried out to determine the phytochemical composition of stem bark extracts of Citrus sinensis and study their anti-hyperglycaemic activities as well as their modulatory effects on starch and sucrose digestion on normal Wistar rats.

Methodology: Stem bark Aqueous (AqE), Ethanolic (EtE), Hydroethanolic (HEE) extracts of C. sinensis were prepared. The content of polyphenols, flavonoids, alkaloids was determined. Antihyperglycaemic activity was evaluated in vivo by oral glucose tolerance test (OGTT) for 120 minutes. Wistar male rats of $180-200 \mathrm{~g}$ were used. After an overnight fast, their glycaemia were measured (T0). Rats were then distributed into five groups of six each: Control (water), Tests (400 mg/kg of each (AqE, EtE, HEE) extracts), Reference (4 mg/kg B. W., glibenclamide). Thirty 
minutes later, an overload of $2 \mathrm{~g} / \mathrm{kg} \mathrm{B}$. W. of glucose was administered to all the groups. Glycaemia was measured by tail pricks: 30, 60, 90, 120 minutes after glucose administration. Sucrose $(2 \mathrm{~g} / \mathrm{kg} \mathrm{B}$. W.), starch (1 g/kg B. W.) and acarbose in co-administration were used as substrates for digestion in a protocol similar to OGTT.

Results: EtE was very rich in polyphenols $(435.56 \pm 3.85 \mu \mathrm{g}$ of eq catechin/mg). Area under the Curves, AUC (mg.min.dL ${ }^{-1}, P=.05$ ) were: 4015, 786.6, 1163 for PC, AqE group, Reference respectively and confirmed that $\mathrm{AqE}$ was more efficient than glibenclamide. AqE also showed moderate efficacy with sucrose (841.2 vs $1172 \mathrm{mg} . \mathrm{min} / \mathrm{dL}, P=.05)$ and starch digestion (892.8 vs $1148 ; P=.05)$ compared to positive controls.

Conclusion: Therefore, stem bark aqueous extract of $C$. sinensis is able to reduce postprandial glycaemia by slowing down the absorption of glucose, challenging the efficacy of glibenclamide,an anti-diabetic drug. Also, AqE has moderate efficacy on starch and sucrose digestion. AqE could thus be further explored for its potency in the treatment of diabetes mellitus.

Keywords: Antihyperglycemia; postprandial glycaemia; stem bark; Citrus sinensis; digestion.

\section{INTRODUCTION}

The incidence of metabolic syndrome (MS) all over the world including Africa is increasing, due to a rise in obesity rates among adults [1-2]. National Heart and Lung Institute [3] reported that in future years, metabolic syndrome may overtake smoking as the leading risk factor for heart disease. Lifestyle, eating habits, sedentarity and urbanization are amongst the factors that contribute to its morbi-mortality $[4,5,6]$. MS is defined as a cluster of cardiovascular risk factors: dyslipidemia, hypertension, abdominal obesity and impaired glucose tolerance or diabetes [7]. The common manifestation of diabetes include hyperglycemia associated or not to insulin resistance. Postprandial hyperglycemia is a predisposing factor for vascular dysfunction and organ damage [8]. It is also associated with long term damage, dysfunction, and failure of various organs, especially the eyes, kidneys, nerves, heart, blood vessels and also an independent risk factor for CVD in patients with or without diagnosed diabetes [9]. Hyperglycemia or PPHG also induces an increase in stiffness of intermediate-sized arteries [10,11,12]. PPHG produces ROS in oxidative stress involved in tissue alteration and disease complications associated with the development of diabetic nephropathy and retinopathy $[13,14]$.

Hyperglycaemia or PPHG also arises from food digestion. Food is the main and natural source of energy with carbohydrates, lipids and proteins being the basic nutritive substances. Digestion and absorption of food lead to hyperglycemia [8-15] followed by a reabsorption period 2-3 hours later in healthy individuals or longer in disease condition $[16,17]$.
Amongst the anti-diabetic medications glucagonlike peptide 1 [GLP-1] receptor agonists, dipeptidylpeptidase -4 [DPP-4] inhibitors have significant benefits in reducing post meal plasma glucose excursions and lowering $\mathrm{HbA} 1 \mathrm{c}$ in people with diabetes through inhibition of digestive enzymes [11-15-18]. Unfortunately, there are many side effects related to these medications, amongst which hyperglycemia associated to glucocorticoid and corticosteroid therapies [19,20,21]. Diabetes treatment and its complications present a significant financial burden for the budget of every developed country [17]. Despite awareness and prevention measures taken by governments to control and reduce mortality, management of diabetes and adequate treatment remain a challenge. The current clinical trend is the utilization of naturally active compounds as replacement therapies and World Health Organization has substantiated their utilization for the management of diabetes $[22,23]$, due to easy availability, economic reasons and lesser side effects [24]. Their use has been reported in Guinea [25], in Morocco [26] and many other countries.

Citrus sinensis (L.) Osbeck (Sweet Orange) is one of the most important and widely grown fruit crop. It accounts for approximately $60 \%$ of Citrus production for both fresh fruit and processed juice consumption. Oranges are an important nutritional source for human health and have immense economic value [27] for its tasty juice and medicinal value [28]. Orange peel extracts have been used to treat colic, upset stomach, cancer, diuretic and to fight diverse viral and bacterial infections [29,30,31]. In addition, only orange peel oil extracts and leave oil extracts of Citrus sinensis was listed amongst over a hundred plants with hypoglycemic and 
antidiabetic effects reported by Udoamaka and Prieto [32]. To date, few or no data on the effect of stem bark extracts on acute treatment of hyperglycaemia and digestion of carbohydrates key substrates have been reported. Therefore, this study was conducted to determine the phytochemical composition of stem bark extracts of Citrus sinensis, study its anti-hyperglycaemic activity and the effect on sucrose and starch digestion on normal Wistar rats.

\section{MATERIALS AND METHODS}

\subsection{Chemicals}

All the chemicals used were of analytical grade and were purchased from Sigma Co., Louis, MO, USA. These include; Folin- ciocalteu reagent, catechin, ethanol, potassium acetate, Quercetin, $\mathrm{FeCl}_{3} ;$ 1, 10-phenanthroline, Acarbose, Glibenclamide.

\subsection{Plant Materials}

Citrus sinensis (L.). Osbeck was harvested in February 2016 in Yaounde, city capital of Cameroon. It was identified at national herbarium with botanical characteristics as described by Letouzey et al. [33] as belonging to Rutaceae family. Stem bark were isolated, cut into small pieces and then shade dried in open air for one month. The dried materials were ground to obtain powder, from which the different extracts were prepared.

\subsubsection{Preparation of ethanolic, aqueous, hyroethanolic extracts}

One hundred grams $(100 \mathrm{~g})$ of stem bark were placed in $800 \mathrm{~mL}$ of ethanol (95\%) for maceration for 48 hours. After filtration, the filtrate was then evaporated at $50^{\circ} \mathrm{C}$ to obtain the ethanolic extracts (EtE). The same procedure was followed to prepare aqueous extract (AqE) and hydroethanolic extracts (HEtE); ethanol been replaced by distilled water and mixture water/ethanol $(95 \%)$ in a ratio of $1: 1$ (v/v) respectively.

\subsection{Quantitative Determination Bioactive Compounds}

The quantitative analysis of some bioactive compounds including polyphenols, flavonoids, alkaloids was done.

\subsubsection{Determination of polyphenolic content}

The polyphenol content was evaluated using the method described by Singleton and Rossi [34].
Briefly, to $30 \mu \mathrm{L}$ of the extract, $1 \mathrm{~mL}$ of the FolinCiocalteu reagent was added. Thirty minutes after the incubation at $25^{\circ} \mathrm{C}$, the absorbance was read at $750 \mathrm{~nm}$ using a spectrophotometer. Catechin was used as standard. The total polyphenol was expressed in microgram equivalence of catechin/mg of extract.

\subsubsection{Determination of total flavonoids' content}

The total flavonoids content was evaluated using the method described by Aiyegoro and Okoh [35]. For each extract, $1 \mathrm{~mL}(1 \mathrm{mg} / \mathrm{mL})$ prepared in ethanol solution, $1 \mathrm{~mL}$ of aluminium chloride, $1 \mathrm{~mL}$ of potassium acetate and $5.6 \mathrm{~mL}$ of distilled water. The mixture was allowed to stand at $25^{\circ} \mathrm{C}$ for 30 minutes. The absorbance of the reaction mixture was read at $420 \mathrm{~nm}$ with a spectrophotometer. Quercetin was used as the standard. The flavonoids content was expressed in $\mathrm{mg}$ equivalence of quercetin/mg of extract.

\subsubsection{Determination of alkaloids' content}

Alkaloid content was evaluated following the method reported by Singh et al. [36]. One hundred (100 mg) milligrams sample powder was mixed with $10 \mathrm{ml}$ of ethanol (80\%). The supernatant was used for the estimation of total alkaloid content. The reaction mixture contained $1 \mathrm{ml}$ extract, $1 \mathrm{ml}$ of $0.025 \mathrm{M} \mathrm{FeCl}_{3}$ in $0.5 \mathrm{M} \mathrm{HCl}$ and $1 \mathrm{ml}$ of $0.05 \mathrm{M}$ of 1,10-phenanthroline in ethanol. The mixture was incubated for 30 minutes using a water bath at the temperature of $70 \pm 2^{\circ} \mathrm{C}$. Absorbance of red coloured complex developed was read at $510 \mathrm{~nm}$ against reagent blank. Alkaloid content was expressed as microgram equivalence of quinine /mg of extract.

\subsection{Animals and Treatments}

Sixty six male albinos' rats weighing 180-200 g were obtained from the Laboratory of Animal physiology, University of Yaoundé 1, Cameroon. Animals were treated according to the ethical guidelines outlined in the Guide for Care and Use committee of the Institutional ethic committee. All protocols were approved by the University of Yaounde 1 Animal Ethics Committee. Animals were housed under standard conditions in cages; $25^{\circ} \mathrm{C}, 50-60 \%$ relative humidity with $12 \mathrm{~h}$ light $12 \mathrm{~h}$ dark cycle. They were fed with a standard diet and received water ad-libitum. All the animals were acclimatized for 10 days prior to the start of the experiment. 


\subsubsection{Study of anti-hyperglycaemic activity: OGTT}

Oral Glucose Tolerance Test (OGTT); an in vivo acute test was conducted as described by Almalki et al. [8], to evaluate the capacity of extracts to prevent the absorption and the rise of glycaemia. Briefly, thirty (30) rats were randomly divided into five groups of six each. After 12 hours overnight fasting, blood glucose at baseline (T0) was measured from vein tails of all rats using a glucometer and test strips (One touch Gluco-plus). Simultaneously, Group 1 serving as control group or Positive Control (PC) was given water orally. Group 2 received Ethanolic Extract $(400 \mathrm{mg} / \mathrm{kg}$ body weight), Group 3 received Aqueous Extract $(400 \mathrm{mg} / \mathrm{kg}$ body weight); Group 4 received Hydroethanolic extract (400 mg/kg body weight); Group 5 received Glibenclamide (4 mg/kg body weight). Thirty (30) minutes after administration of extracts, animals in all the groups were given overload glucose solution (2 $\mathrm{g} / \mathrm{kg}$ body weight). Blood glucose levels were measured using glucometer through tail pricks at $30,60,90$ and 120 minutes after glucose loading. Administration of extracts and glucose was done orally with water, $5 \mathrm{~mL} / \mathrm{kg} \mathrm{b}$. w.

\subsubsection{In vivo study of the effects of aqueous extract on sucrose and starch digestion}

The protocol used was similar to OGTT with some modifications. Briefly, animals were randomly divided into three groups of six animals each. After 12 hours overnight fasting, blood glucose at baseline (T0) was measured from vein tails of all rats using a glucometer and test strips (One touch Gluco-plus). Simultaneously, Group 1 or Positive Control (PC) was given water $+2 \mathrm{~g} / \mathrm{kg}$ sucrose orally. Group 2 received Aqueous Extract $(400 \mathrm{mg} / \mathrm{kg}$ body weight $+2 \mathrm{~g} / \mathrm{kg}$ sucrose); Group 3 received Acarbose $3 \mathrm{mg} / \mathrm{kg} \mathrm{B}$. $\mathrm{W}+2 \mathrm{~g} / \mathrm{kg} \mathrm{B}$. W sucrose). Blood glucose levels were measured using a glucometer through tail pricks at 30,60 , and 120 minutes after sucrose loading. A similar design was implemented to study starch digestion as described above, except that starch $1 \mathrm{~g} / \mathrm{kg} \mathrm{B}$. W replaced sucrose and the follow up was done at $60,90,120,180$ minutes. Administration of extracts and substrates (sucrose, starch) was done at the same time to allow the interactions between extracts, substrates and enzymes in the gastrointestinal track. Blood glucose was measured as end products from starch and sucrose digestion and absorption.

\subsection{Data Processing and Analysis}

Results were expressed as incremental change and as Mean \pm Standard Deviation. Graphpad prism software, version 6.0 (GraphPad Prism INC., CA, USA) was used to determine the area under the curve (AUC) as an expression of efficacy of extracts. Statistical Package for Social Science (SPSS 20.0 Illinois, Chicago) was used to analyze results. Paired sample Student-t-test was used to analyze blood glucose levels for each extract at each time. One-way analysis of variance ANOVA test followed by Waller-Dunkan as post-hoc was used to compare variables between groups under $95 \%$ confidence interval.

\section{RESULTS AND DISCUSSION}

\subsection{Results}

\subsubsection{Phytochemical content}

The phytochemical analysis of Citrus sinensis stem bark extracts obtained using different soft solvent systems; water, ethanol and Waterethanol mixture $(1: 1 \mathrm{v} / \mathrm{v})$ revealed larger quantities of polyphenolic compounds in all the extracts, the ethanolic extracts being richer than the aqueous and hydroethanolic extracts. However, hydroethanolic and ethanolic extracts possess a higher content of alkaloids. Flavonoids were higher in ethanolic extracts (Table 1).

Table 1. Phytochemical content of $C$. sinensis stem bark extracts

\begin{tabular}{|c|c|c|c|}
\hline Compounds & Aqueous & Hydro ethanolic & Ethanolic \\
\hline Alkaloids ( $\mu \mathrm{g}$ EqQuinine/mg) & $4.34 \pm 0.6^{\mathrm{a}}$ & $13.13 \pm 1.6^{\mathrm{b}}$ & $13.18 \pm 1.6^{b}$ \\
\hline Polyphenols ( $\mu \mathrm{g}$ Gallic acid/mg) & $208.89 \pm 25.24^{a}$ & $406.67 \pm 57.74^{b}$ & $435.56 \pm 3.85^{b}$ \\
\hline Flavonoids ( $\mu \mathrm{g}$ Eq Quercetin/mg) & $0.85 \pm 0.05^{\mathrm{a}}$ & $1.16 \pm 0.15^{\mathrm{b}}$ & $9.40 \pm 0.70^{\mathrm{b}}$ \\
\hline
\end{tabular}

Results expressed as Mean $\pm S D$, Tests were done in triplicates, eq: equivalent; variables with different letters a, $b, c$ associated are significantly different $P=.05$ 
3.1.2 Anti-hyperglycaemic effects of $C$. sinensis stem bark extracts

Administration of glucose to rats receiving no extracts resulted in highest peak at $30 \mathrm{~min}$ and thereafter a gradual reduction of glycaemic levels with time. All other groups showed a peak at 30 min lower than PC. Values gradually decreased during the experiment. It clearly appears that aqueous extracts of $C$. sinensis was able to prevent the increase of blood glucose. The values were lower compared to positive control, and interestingly, lower compared to glibenclamide, antidiabetic drug of reference (Fig. 1).

\subsubsection{Variation of blood glucose in each group within two hours experiments}

With paired-sample Student $t$ test, it is observed that acute administration of each extract during thirty minutes revealed significant increase of $82.24 \%$ in PC compared to $23.49 \%$ in AqE group
1 in all the groups except the group receiving glibenclamide. The decrease in groups treated with glibenclamide (-16.07\%) and AqE (-21.81\%) was significant after two hours compared to baseline Glycaemia (Table 2).

\subsubsection{Comparison inter groups at each time intervals}

An adjustment from glycemic levels at baseline showed the trends of each extract in comparison with positive control group and with glibenclamide, anti-diabetic drug (Fig. 2).

Statistical analysis with ANOVA and WallerDuncan post hoc test revealed that at each time interval, there was a significant difference between blood glucose increment of PC group and all the treated groups and with Glibenclamide, reference group. At 60 minutes the group receiving $\mathrm{AqE}$ significantly decreased blood glucose $(P=.05)$ than the group treated with glibenclamide (Fig. 2).

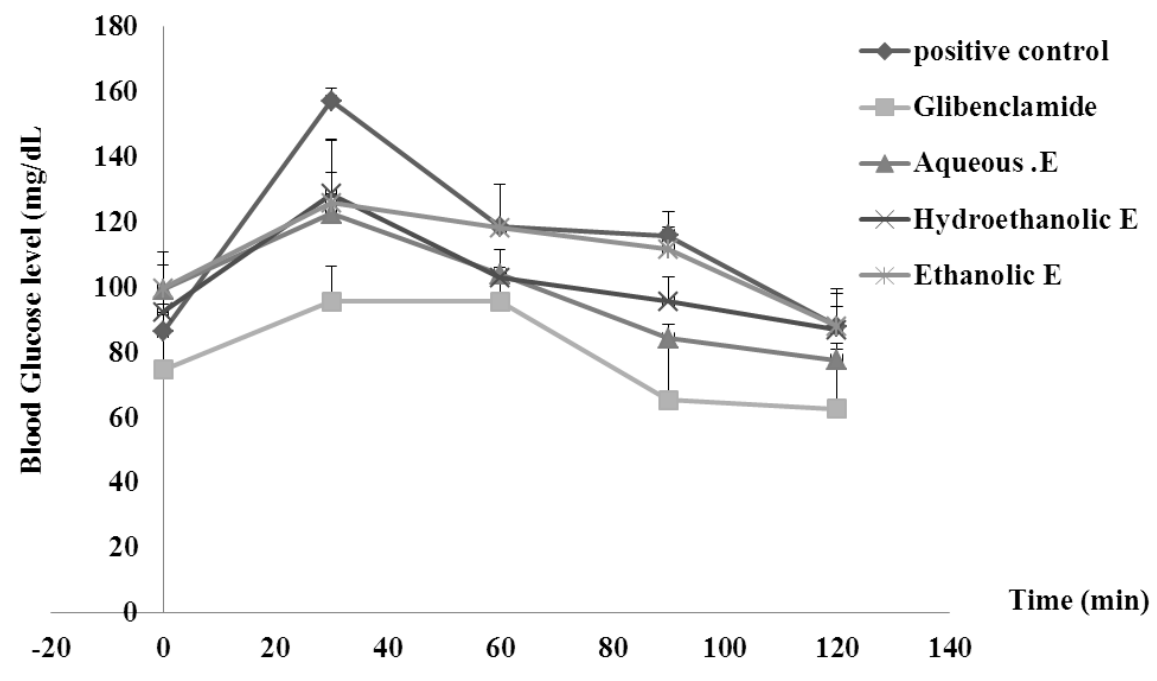

Fig. 1. Effect of stem bark extracts on blood glucose level Results are expressed Mean +/- SD, $n=5$ rats/group

Table 2. Percentage variation within time intervals

\begin{tabular}{lllllll}
\hline \multirow{2}{*}{ Groups } & \multicolumn{2}{c}{ Variation T0 - T30 } & \multicolumn{2}{c}{ Variation T30 - T120 } & \multicolumn{2}{c}{ Variation (T0-T120) } \\
\cline { 2 - 7 } & \%variation & $\boldsymbol{P}$ value & \%variation & $\boldsymbol{P}$ value & \%variation & $\boldsymbol{P}$ value \\
\hline Positive control & 82.24 & $<.001$ & -44.07 & .001 & 1.93 & .778 \\
Glibenclamide & 28.13 & .093 & -34.49 & .026 & -16.07 & .05 \\
EtE & 26.42 & .002 & -30.16 & .008 & -11.71 & .06 \\
$\mathrm{HEE}$ & 39.35 & .001 & -32.38 & .001 & -5.78 & .286 \\
$\mathrm{AqE}$ & 23.49 & .006 & -36.68 & .004 & -21.81 & .004 \\
\hline \multicolumn{2}{c}{ Stem bark Aqueous (AqE), Ethanolic (EtE), Hydroethanolic (HEE) extracts of C. Sinensis }
\end{tabular}




\subsubsection{Efficacy of Citrus sinensis extracts}

The efficacy of each extract measured as AUC confirmed that stem bark Aqueous Extract has the lowest AUC compared to PC and more interestingly to glibenclamide. All other extracts showed an AUC lower than Positive Control (Fig. 3).

\subsubsection{Effects of extract on sucrose digestion}

Based on results above, Aqueous Extract (AqE) being the best antihyperglycaemic extract was selected for digestion studies. Administration of sucrose (only), to rats increased blood glucose within $30 \mathrm{~min}$ (variation of $13.66 \mathrm{mg} / \mathrm{dL}$ ). After an hour, sucrose was completely digested and glucose released, absorbed in PC group. In the presence of AqE, there was a delay of 90 minutes in the digestion/release of glucose from sucrose before glucose started subsequently appearing in the blood, to reach a peak after 2 hours (15.33 mg/dL). AqE demonstrated its ability to inhibit digestion of sucrose and promoted the shift of peak appearance from 30 min with sucrose only (PC) to $120 \mathrm{~min}$ in presence of AqE (Fig. 4).

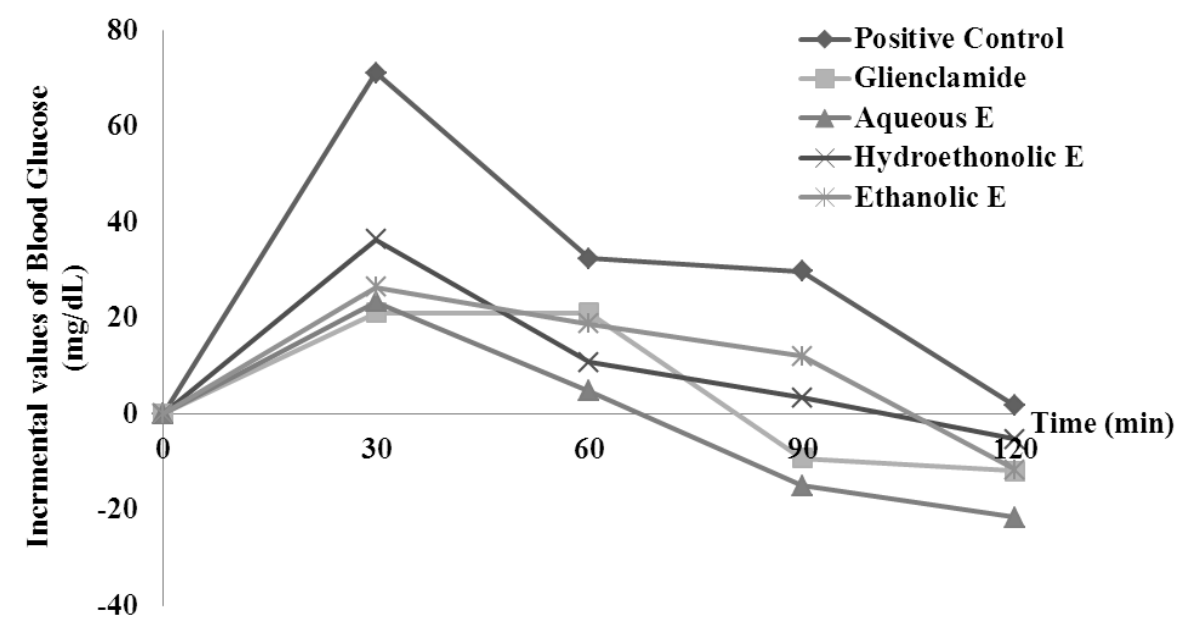

Fig. 2. Effects of $C$. sinensis stem back extracts on regulation of overload glucose adjusted from baseline

Results expressed as Mean \pm Standard deviation; $n=6$ rats/group

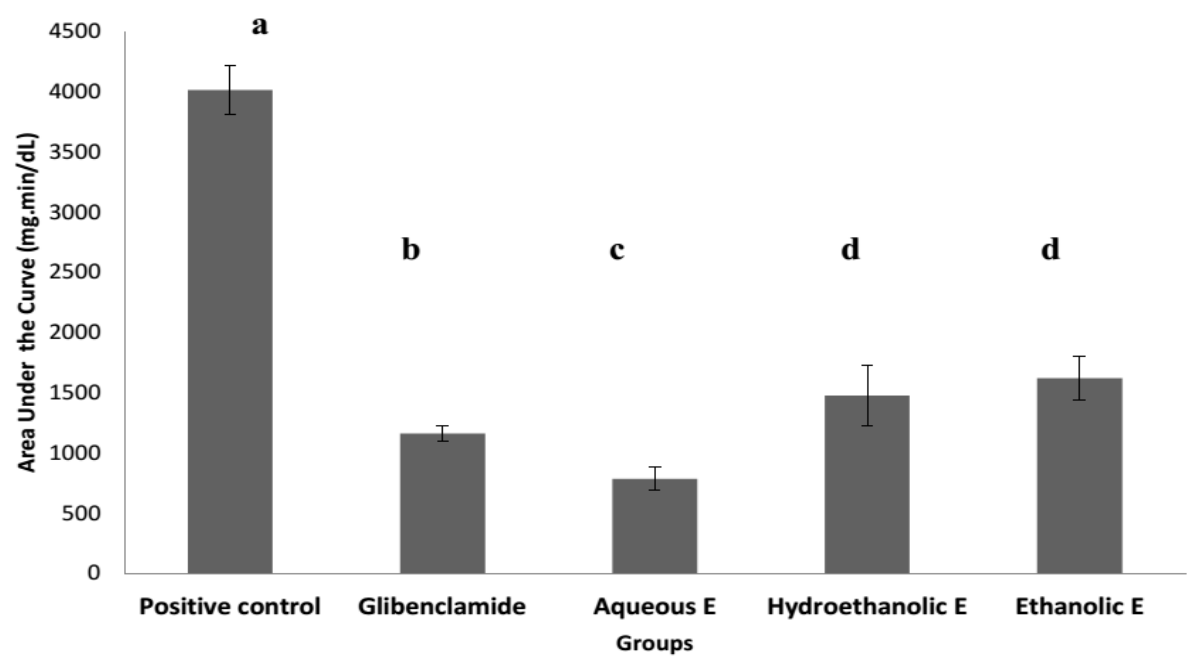

Fig. 3. Efficacy of stem bark extracts of $\boldsymbol{C}$. sinensis on overload glucose

Results expressed as Mean \pm Standard deviation; $n=6$ rats/group; bar graphs with different letters $a, b, c, d$ associated are significantly different $P=0.5$ 


\subsubsection{Efficacy of aqueous extract on sucrose digestion}

After two hours experiment, the efficacy of AqE was lower than positive control as confirmed by AUC values. However, acarbose showed highest efficacy (Fig. 5).

\subsubsection{Effects of aqueous extracts on starch digestion}

In Fig. 6, It has been observed that in the absence of $\mathrm{AqE}$ or reference drug, starch is digested into its monomers of glucose leading to blood glucose rise within an hour to $22.66 \mathrm{mg} / \mathrm{dL}$ (PC) followed by a consistent digestion and absorption all through the experiment.
With co-administration of AqE, digestion within the first hour is similar to $P C(P>.05)$. But, between 60 to $90 \mathrm{~min}$, digestion of starch is slowed down at a rate greater than PC group to become constant $90 \mathrm{~min}$.

\subsubsection{Efficacy of aqueous extract on starch digestion}

The efficacy of acarbose $(P=.05)$ was greater than the efficacy of the group treated with AqE which had moderate activity compared to Positive Control (PC, $P=.05$ ). The efficacy of $\mathrm{AqE}$ was $-35 \%$ compared to acarbose (Fig. 7).

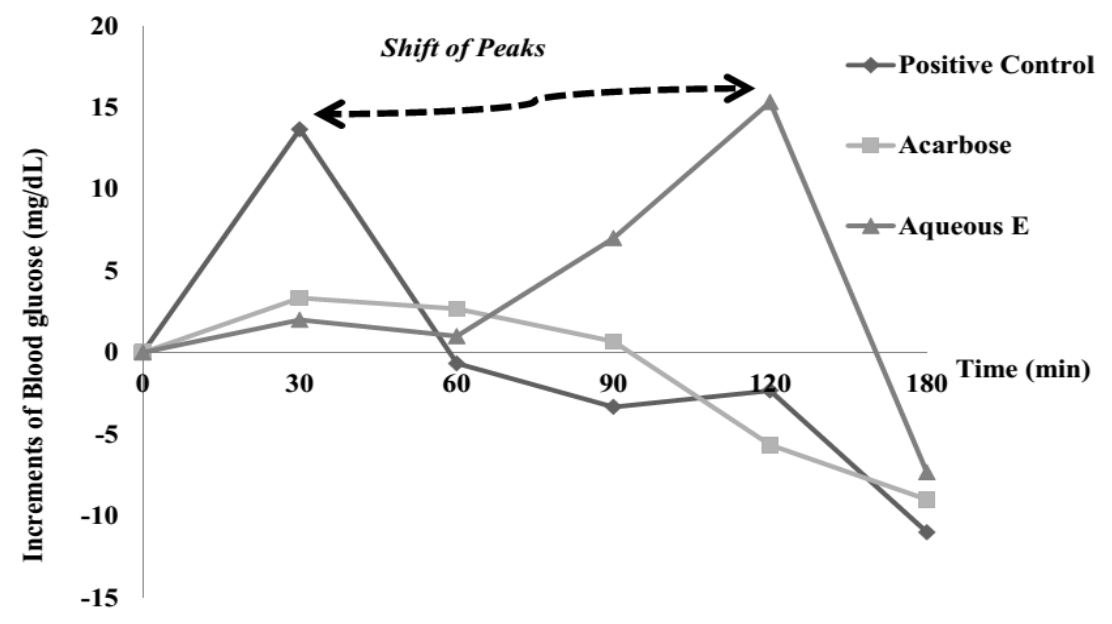

Fig. 4. Effects of aqueous extract on sucrose digestion in vivo Results were expressed as incremental difference ( $m g / d L) . n=6$ rats

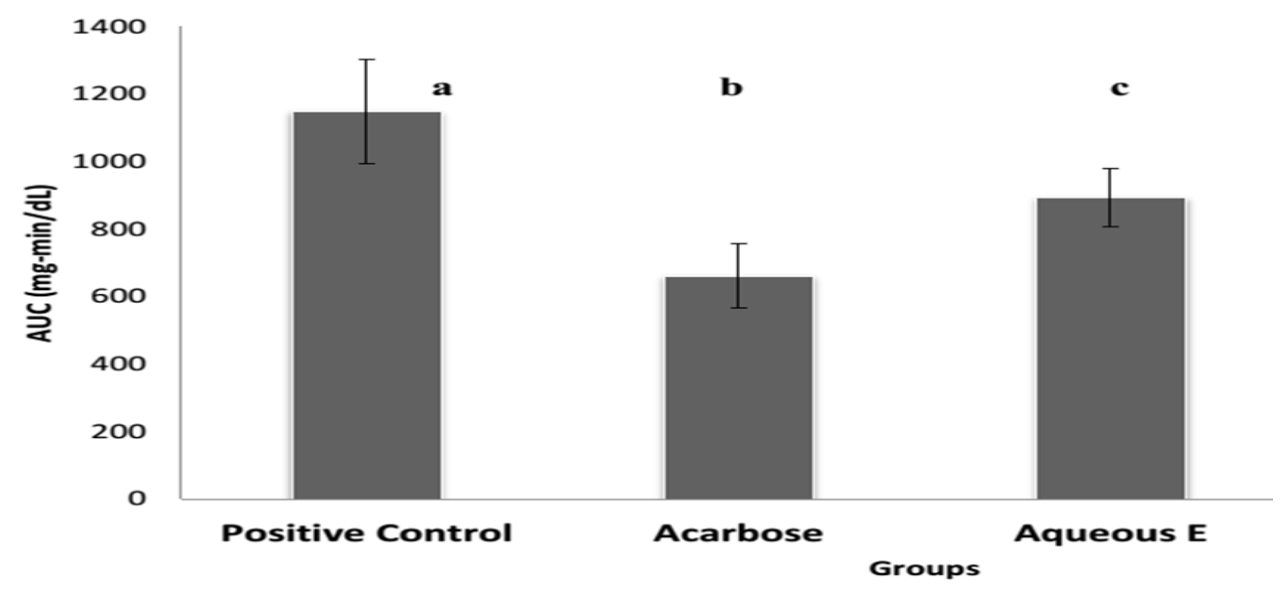

Fig. 5. Efficacy of aqueous extract on sucrose digestion

Results expressed as Mean \pm Standard deviation; $n=6$ rats/group; bar graphs with different letters $a, b, c$ associated are significantly different $P=0.5$ 


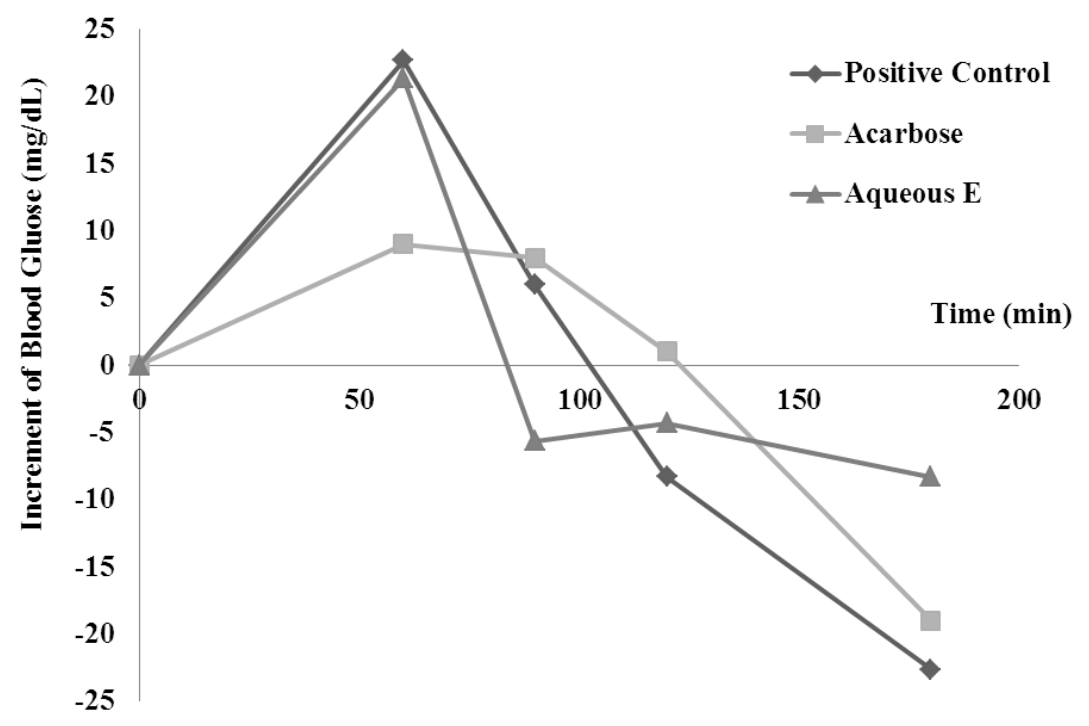

Fig. 6. Effects of aqueous extracts on starch digestion

Results were expressed as incremental difference ( $\mathrm{mg} / \mathrm{dL}$ ). $n=6$ rats/ groups

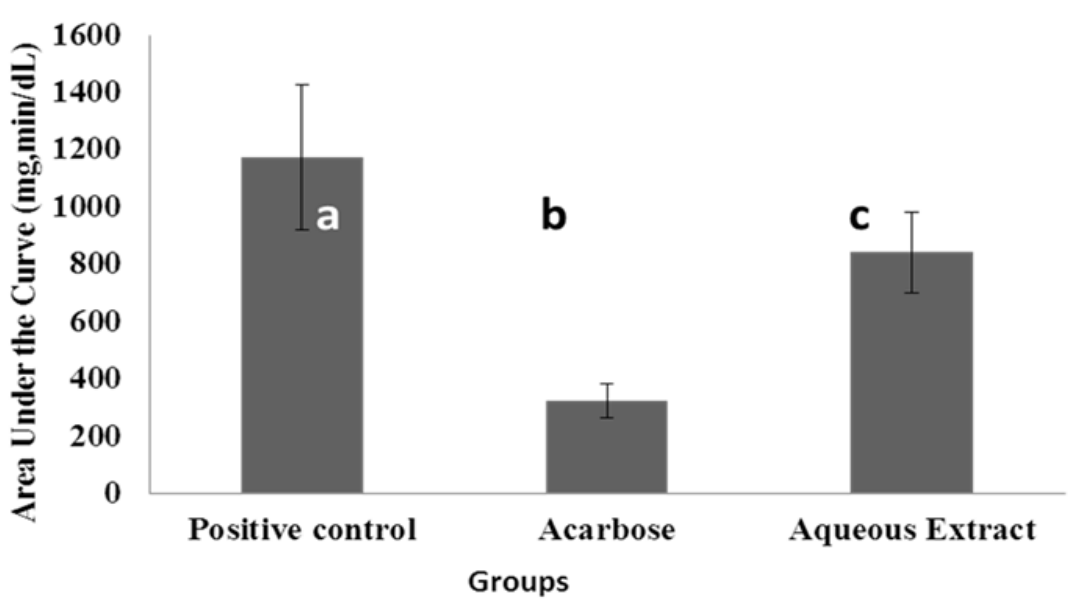

Fig. 7. Efficacy of Aqueous Extract on starch digestion in vivo

Results were expressed as mean $\pm S D$. $n=6$ rats/group; AUC: Area under the Curve, Different histograms different letters $a, b, c$ associated are significantly different $P=0.5$

\subsection{Discussion}

Metabolic syndrome including obesity and diabetes as individual components is the most prevailing health concern worldwide and its incidence is increasing at a high rate, resulting in enormous social costs [2-37]. Control of glycemic excursions is an approached to manage MS. This study demonstrated the ability of Aqueous Ethanolic and Hydroethanolic stem bark extracts of $C$. sinensis to gradually and effectively reduce post prandial glycaemia compared to a Positive Control (Figs. 1,3). It can be speculated that the efficacy of the extracts can be helpful in the prevention and management of diabetes and its complications. In this study, Citrus sinensis extracts revealed their high content in polyphenols, flavonoids and alkaloids (Table 1); compounds that could justify the efficacy of extracts in reducing blood glucose or preventing its increase (Figs. 1, 2, 3). Numerous in vitro cell and in vivo animal studies support the beneficial effects of dietary flavonoids on glucose homeostasis for the prevention and treatment of obesity and diabetes [38] by regulation of carbohydrate digestion, adipose deposition, insulin release and glucose uptake in insulinresponsive tissues through numerous cell- 
signaling pathways [37]. Flavonoids and polyphenols could alleviate chronic hyperglycaemia and by so doing prevent insulin resistance and oxidative stress found in the complex and heterogeneous condition of diabetes [39]. Aqueous Extract was the most efficacious amongst the extracts (Table 2) though its polyphenols, alkaloids, flavonoids content was smaller than in EtE and HEE (Table 1). Its efficacy was higher compared to glibenclamide, an antidiabetic drug used as reference (Figs. 2, 3). AqE may be rich in bioactive compounds acting via mechanism similar to glibenclamide with better effectiveness. Glibenclamide, a 5-chloro-N-(2-\{4[(cyclohexylamino) carbonyl] aminosulfonyl\} phenyl)ethyl)-2-methoxybenzamide is a secondgeneration sulfonylurea that reduces blood glucose by binding to the specific receptor for sulfonylureas on $\beta$-pancreatic cells, blocking the inflow of potassium $\left(\mathrm{K}^{+}\right)$through the ATPdependent channel. The resulting increased flow of calcium into $\beta$-cells causes the contraction of the filaments of actomyosin and prompt secretion of insulin in large amounts $[40,41,42]$. Although the aqueous extract is just a crude extract, it can be speculated that flavanones such as naringenin and hesperidin abundant in Citrus fruits such as grape, tomatoes and oranges are reported to possess antioxidant, anti-diabetic properties [43] could be also found in their stem bark. In addition, AqE may also reduce glucose absorption through interaction with, GLUT2, the predominant glucose transporter in the intestine [44].

An indirect appreciation of the aqueous extract on invertase an alpha amylase was evaluated on the basis of the correlation existing between in vitro and in vivo studies on glucose response and portal glucose appearance up to $8 \mathrm{~h}$ post meal [45]. This study revealed that stem bark AqE of C. sinensis was able to moderately slow down the digestion-absorption process of starch (Figs. 6 and 7) and sucrose (Figs. 4 and 5) compared to PCs. This is result is in accordance with drugs used to treat metabolic disease such as obesity / diabetes. They act in gastrointestinal tract (GIT) to inhibit key enzymes of the digestive system including alpha glucosidase, invertase and alpha amylase [46,47]. The moderate effects $\mathrm{AqE}$ is important because in humans, between $40 \%$ and $80 \%$ of total caloric intake is accounted for by carbohydrates in their various forms making them the most important energy source [46]. Starch is digested primarily to maltose and other short chain carbohydrates by salivary and pancreatic amylase [43-46] and postprandial glycaemia occurs as a result of absorption of monosaccharide mainly glucose. Interference of AqE with those enzymes reduces postprandial glycaemia.

Sucrose concentration of approximately $1.11 \mathrm{M}$ administered in this experiment probably led to glucose and fructose appearing in the serosal compartment of rats at similar rates of serosal transfer as proven ex vivo by Ruth and Leese [48]. AqE interfering with sucrose digestionabsorption was proven to slow down digestion and delayed absorption (Fig. 4). Such delay can be helpful for the acute treatment of diabetes /or of glucose excursions in patients; mainly in condition of diabetes where consumption of diet with high glycemic index can lead to coma in very short period. The delay may also give time to hormones and enzymes to be secreted in amount higher enough to stimulate the uptake of glucose and better promote its plasma clearance in normal or diabetic rats, given that the status normal or diabetes does not alter the GIT functions [49].

Although the efficacy of AqE was lesser (-35\%) compared to reference drug acarbose (Fig. 5). It can be speculated that aqueous extract of stem bark of $C$. sinensis in its constituents can act through inhibition of invertase and alpha amylase. In fact, polyphenolic compounds present (Table 1) have been shown to possess antioxidant actions and to be able to inhibit digestive enzymes. Naturally occurring polyphenols, in particular catechins and condensed tannins isolated from various plant sources have been shown to inhibit digestive enzymes including lipase and $\alpha$-amylase in vitro [50]. Also, Aq extract may possess molecules which could act with mechanisms similar to acarbose given that acarbose, $\mathrm{C} 25 \mathrm{H} 43 \mathrm{NO} 18$ is a pseudo-tetrasaccharide that inhibits intestinal a-glucosidase reversibly at the brush border of intestinal mucosa. As a consequence, the digestion of disaccharides to monosaccharides is prevented, the uptake of monosaccharides is retarded and thus postprandial insulin and glucose levels are reduced [50]. The inhibition of the enzymes delays the degradation of oligosaccharides to glucose, and therefore controls postprandial hyperglycemia [47]. Such action mechanism may explain the shift of peaks from $30 \mathrm{~min}$ to $1 \mathrm{~h} 30$ minutes observed on sucrose digestion (Fig. 4). Moreover, the faster digestion (Fig. 5) of substrate by extracts followed by their rapid absorption in acute test 
(Fig. 2, Table 2) may avoid the gastrointestinal side-effects which unfortunately hampered the usage of acarbose, despite its good safety record [47].

Flavonoids, polyphenols, alkaloid found in Aqueous Extract probably contributed to its moderate efficacy on starch digestion and inhibition. In fact, black tea polyphenols exert a positive effect on inhibiting obesity through two major mechanisms: inhibiting lipid and saccharide digestion, absorption and intake; thus reducing calorie intake [51]. Lochocka et al. [52] reported that a single dose of green tea extract taken with a test meal decreases starch digestion and absorption. Also, Haibo et al. [51] and Hara et al. [53] in another study reported that the aflavins showed stronger inhibitory effect on GIT enzymes than catechins. Such flavonoids mainly inhibit only GLUT2 but not SGLT1 [54].

Many other studies have reported on the use of herbs/medicinal plants that interfere with carbohydrate digestion and absorption [37-43], including a Vietnamese Citrus Peels of "Buddha's hand", another Rutaceae, whose essential oil strongly inhibited a-glucosidase activity in a dose dependent manner [47-55].

\section{CONCLUSION}

Aqueous (AqE), Ethanolic (EtE), Hydroethanolic (HEE) stem bark extracts of $C$. sinensis with their rich phytoconstituents, reduce postprandial glycaemia by slowing down absorption of glucose. Anti-hyperglycemic efficacy of aqueous extract challenges glibenclamide, anti-diabetic drug. AqE moderately interferes on starch and sucrose digestion. Stem bark AqE of Citrus sinensis could thus be further explored for its potency in the treatment of diabetes mellitus and other metabolic disorders.

\section{COMPETING INTERESTS}

Authors have declared that no competing interests exist.

\section{REFERENCES}

1. $\mathrm{Ng} \mathrm{M}$, Fleming $\mathrm{T}$, Margaret $\mathrm{R}$, Blake $\mathrm{T}$, Nicholas G, Christopher M, Erin CM, Stan $B$, Cristiana A, Jerry PA, Niveen ME, AbuRmeileh, et al. Global, regional, and national prevalence of overweight and obesity in children and adults during 1980-
2013: A systematic analysis for the global burden of disease study. The lancet. 2014; 384(9945):766-781.

2. Šimunović $M$, Joško $B$, Lukrecija $M$, Ivana $\mathrm{U}$, Veselin Š. The prevalence of metabolic syndrome and cardiovascular risk factors in obese children and adolescents in Dalmatia: A hospital based study. International Journal of Endocrinology. 2016;1-7.

3. National heart and lung institute. What is metabolic syndrome? 2016.

Available:https://www.nhlbi.nih.gov/health/ health-topics/topics/ms

4. Ntentie FR, Ngondi JL, Azantsa KBG, Santy EV, Dimodi HT, Mbong AMA, Chakokam NRM, Nguimkeng SB, Zambou $\mathrm{H}$, Oben EJ. Urbanization and metabolic syndrome in Cameroon: Alertness on less urbanised areas. Endocrinology and Metabolic Syndrome. 2014;3(3):1-8.

5. Maire $B$, Delpeuch $F$. La transition nutritionnelle, l'alimentation et les villes dans les pays en développement. Agricultures : Cahiers d'Etudes et de Recherches Francophones. 2004;13(1): 23-30.

6. Jagmeet GM, Ankita MN. Prevalence of metabolic syndrome in Mumbai City, India. Journal of Obesity and Metabolic Research. 2016;3(1):16-22.

7. Suarez-Ortegón MF, Aguilar-de Plata C. Prevalence of metabolic syndrome in children aged 5-9 years from southwest Colombia: A cross-sectional study. World Journal of Pediatrics. 2016;12(4):477-483.

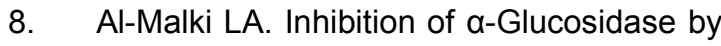
Thiosulfinate as a target for glucose modulation in diabetic rats. EvidenceBased Complementary and Alternative Medicine. 2016;1-5.

9. Mahato VR, Gyawali P, Raut PP, Regmi P, Singh KP, Raj PDP, et al. Association between glycaemic control and serum lipid profile in type 2 diabetic patients: Glycated haemoglobin as a dual biomarker. Biomedical Research. 2011;22(3):375-80.

10. Bonora E, Muggeo M. Postprandial blood glucose as a risk factor for cardiovascular disease in type 2 diabetes: The epidemiological evidence. Diabetologia. 2001;44:2107-2114.

11. Gordin D, Markku S, Jaana T, Aino SP, Carol F, Karri P, Birgit SH, Francois V, Loizos N, Imre P. Influence of postprandial hyperglycemic conditions on arterial 
stiffness in patients with type 2 diabetes. Journal of Clinical Endocrinology and Metabolism. 2016;101(3):1134-1143.

12. Sharma SK, Panneerselvam A, Singh KP, Parmar G, Gadge P, Swami OC. Teneligliptin in management of type 2 diabetes mellitus. Diabetes, Metabolic Syndrome and Obesity: Targets and Therapy. 2016;9:251-260.

13. Hurel SJ, Mohan V. Clinical decision making: Managing postprandial hyperglycemia. Journal of the Association of Physician of India. 2006;54:871-876.

14. Deiscas A, Gregg CF, Mihai G, Javed B. Concomitant diabetes mellitus and heart. Failure. Current Problems in Cardiology. 2015;40(1):7-43.

15. Gerich J. Pathogenesis and management of postprandial hyperglycemia: Role of incretin-based therapies. International Journal of General Medicine. 2013;6:877895.

16. Heine RJ, Balkau B, Ceriello A, et al. What does postprandial hyperglycaemia mean? Diabetic Medicine. 2004;21(3):208-213.

17. Strojek K, Liliana M, Dorota Z, Janusz G, Janusz K, Maciej M. Postprandial glycemia: Review of current pathophysiological, epidemiological and clinical aspects. Polskie Archiwum Medycyny Wewnętrznej. 2007;7(5-6):1-6.

18. Barkai L, Nicolae H, György J, Maya K, Radu L, Maria M, Cvetalina T, Natalia T, Gábor W. The importance of postprandial hyperglycemia position statement of the Danube Mco experts. Romanian Journal of Diabetes Nutrition and Metabolic Diseases. 2015;22(1).

19. Umpierrez GE, Kitabbhi AE. ICU care for patients with diabetes. Current Opinion In Endocrinology, Diabetes and Obesity. 2004;11:75-81.

20. Umpierrez GE, Richard $H$, Mary TK, Mikhail K, Gregory AM. Victor MM, Jane JS, Van den Berghe G. Management of hyperglycemia in hospitalized patients in non-critical care setting: An endocrine society clinical practice guideline. Journal of Clinical Endocrinology and Metabolism. 2012;97(1):16-38.

21. Moghissi ES, Korytkowski MT, DiNardo M, Einhorn D, Hellman R, Hirsch IB, Inzucchi SE, Ismail-Beigi F, Kirkman MS, Umpierrez GE. American association of clinical endocrinologists and American diabetes association consensus statement on inpatient glycemic control. Diabetes care. 2009;32(6):1119-1131.

22. Benkeblia N, Shinano $T$, Osaki M. Metabolite profiling and assessment of metabolome compartmentation of soybean leaves using non-aqueous fractionation and GC-MS analysis. Metabolomics. 2007; 3(3):297-305.

23. Bailey CJ, Day C. Traditional plant medicines as treatments for diabetes. Diabetes Care. 1989;12:553-64.

24. Zayneb A, Hayat A, Bouchra A, Youssef H, Hanane L. Herbal medicines use among diabetic patients in Oriental Morocco. Journal of Pharmacognosy and Phytotherapy. 2015;7(2):9-17.

25. Baldé NM, Youla A, Baldé MD, Kaké A, Diallo MM, Baldé MA, Maugendre D. Herbal medicine and treatment of diabetes in Africa: An example from Guinea. Diabetes and Metabolism. 2006;32(2): 171-175.

26. Barkaoui M, Katiri A, Boubaker $\mathrm{H}$, Msanda F. Ethnobotanical survey of medicinal plants used in the traditional treatment of diabetes in Chtouka AitBaha and Tiznit (Western Anti-Atlas), Morocco. Journal of Ethnopharmacology. 2017;23(198):338350.

27. $\mathrm{Xu} Q$, Ling-Ling $\mathrm{C}$, Xiaoan $\mathrm{R}$, Dijun $\mathrm{C}$, Andan Z, Chunli C, Denis B, Wen-Biao J, Bao-Hai $\mathrm{H}$, et al. The draft genome of sweet orange (Citrus sinensis). Nature Genetics. 2012;45:59-66.

28. Shakthi DA, Sathish KT, Kumaresan K, Rapheal VS. Extraction process optimization of polyphenols from Indian Citrus sinensis - as novel antiglycative agents in the management of diabetes mellitus. Journal of Diabetes and Metabolic Disorders. 2014;13:11.

29. Grosso G, Galvano F, Mistretta A, Marventano S, Nolfo F, Calabrese G. Red orange: Experimental models and epidemiological evidence of its benefits on human health. Oxidative Medicine Cellular Longevity. 2013;157240.

30. Hussain KA, Tarakji B, Kandy BP, John J, Mathews J, Ramphul V, Divakar DD. Antimicrobial effects of Citrus sinensis peel extracts against periodontopathic bacteria: An in vitro study. Rocz Panstw Zakl Hig. 2015;66(2):173-8.

31. Shetty SB, Prabu MSI, Shaji V, Bibin TG, Pathinettam KTH, Deepak B, Shaista $H$, Sreeja S, Darshan DD. Antimicrobial 
effects of Citrus sinensis peel extracts against dental caries bacteria: An in vitro study. Journal of Clinical and Experimental Dentistry. 2016;8(1):71-77.

32. Udoamaka FE, Prieto JM. The use of plants in the traditional management of diabetes in Nigeria: Pharmacological and toxicological considerations. Journal of Ethnopharmacology. 2014;155(2):857-92.

33. Letouzey R. Identification of tropical woody plants in the absence of flowers and fruits; 1961.

Available:www.mobot.org/mobot/research/ apweb/top/referencesi p.html

34. Singleton V, Rossi J. Colorimetric of total phenolics with phosphomolybdicphosphotungstic acid reagents. AJEV. 1965;16:144-158.

35. Aiyegoro OA, Okoh I. Preliminary phytochemical screening and in vitro antioxidant activities of the aqueous extract of Helichrysum longifolium. BMC Complement Alternative Medicine. 2010; 10:21.

36. Singh DK, Srivastva B, Sahu A. Spectrophotometric determination of Rauwolfia alkaloids, estimation of reserpine in pharmaceuticals. Analytical Science. 2004;20:571-573.

37. Hossain MK, Ahmed AD, Jihae H, Yingfu Y, Kyeongseok K, Subbroto KS, GwangMo Y, Hye YC, Ssang-Goo C. Molecular mechanisms of the anti-obesity and antidiabetic properties of flavonoids. International Journal of Molecular Sciences. 2016;17(4):569.

38. Rehman U, Choi MS, Choe K, Yoo HH. Interactions between herbs and antidiabetics: An overview of the mechanisms, evidence, importance and management. Archives of Pharmacal Research. 2015;38(7):1281-1298.

39. Sacco F, Sean JH, Jurgen C, Marcel M, Anke S, Thomas K, Matthias S, Matthias M. Glucose-regulated and drug-perturbed phosphoproteome reveals molecular mechanisms controlling insulin secretion. Nature Communications. 2016;7:1-13.

40. Rambiritch V, Breminand M, Poobalan N. Glibenclamide in patients with poorly controlled type 2 diabetes: a 12-week prospective single-center open-label doseescalation study. Clinical Pharmacology. 2014;6:63-69.

41. Sanz D, Claramunt RM, Alkorta I, Sánchez-Sanz G, Iguero E. The structure of glibenclamide in the solid state. Magnetic Resonance in Chemistry. 2012;50(3):246-255.

42. Sola D, Luca R, Gian PCS, Pamela M, Marcello B, Roberto M, Francesca C, Gian PF, Ettore B, Giuseppe D. Sulfonylureas and their use in clinical practice. Archives of Medical Science. 2015;11(4):840-848.

43. Jung UJ, Lee MK, Park YB, Kang MA, Choi MS. Effect of citrus flavonoids on lipid metabolism and glucose-regulating enzyme mRNA levels in type-2 diabetic mice. International Journal of Biochemistry and Cell Biology. 2006;38(7):1134-1145.

44. Malunga LN, Peter Eck, Trust B. Inhibition of intestinal $\alpha$-glucosidase and glucose absorption by feruloylated arabinoxylan Mono- and oligosaccharides from corn bran and wheat aleurone. Journal of Nutrition and Metabolism. 2016;1-9.

45. Theo ATG, Van K, Prajwal RR, Matte JJ, Ruurd TZ. In vitro starch digestion kinetics corrected for estimated gastric emptying predict portal glucose appearance in pigs. The Journal of Nutrition. 2010;140(7): 1227-1233.

46. Grabitske HA, Slavin JL. Gastrointestinal effects of low-digestible carbohydrates. Crit Rev Food Sci Nutr. 2009;49(4):327-60.

47. Nguyen HD, Pham HN, Bui TMA, Dinh TTTH, Chau VM, Nguyen TD. Chemical composition and a-glucosidase inhibitory activity of Vietnamese citrus peels Essential Oils. Journal of Chemistry. 2016;1:52016.

48. Ruth ED, Leese HJ. Sucrose absorption by the rat small intestine in vivo and in vitro. Journal of Physiology. 1977;267(1):237248.

49. Arvanitakis C, Olsen WA. Intestinal digestion and absorption of sucrose in experimental diabetes. Acta Diabetologia Latina. 1976;13(3-4):154-7.

50. Tucci SA, Emma JB, Jason CGH. The role of lipid and carbohydrate digestive enzyme inhibitors in the management of obesity: A review of current and emerging therapeutic agents. Diabetes, Metabolic Syndrome and Obesity: Targets and Therapy. 2010;3: 125-143.

51. Haibo P, Ying G, Youying T. mechanisms of body weight reduction by black tea polyphenols. Molecules. 2016;21(12): 1659. 
52. Lochocka K, Joanna B, Aleksandra G, Ewa F-W, Jan KN, et al. Green tea extract decreases starch digestion and absorption from a test meal in humans: a randomized. Placebo-controlled crossover study. Science Reports. 2015;5:12015.

53. Hara $Y$, Honda $M$. The Inhibition of $\alpha-$ amylase by tea polyphenols. Agricultural and Biological Chemistry. 2014;54(8): 1939-1945.
54. Kwon O, Eck P, Chen S, et al. Inhibition of the intestinal glucose transporter GLUT2 by flavonoids. The FASEB Journal. 2007;21(2):366-377.

55. Hasanein P, Fazeli F. Role of naringenin in protection against diabetic hyperalgesia and tactile allodynia in male wistar rats. Journal of Physiology and Biochemistry. 2014;70(4):997-1006.

(c) 2017 Boris et al.; This is an Open Access article distributed under the terms of the Creative Commons Attribution License (http://creativecommons.org/licenses/by/4.0), which permits unrestricted use, distribution, and reproduction in any medium, provided the original work is properly cited.

Peer-review history:

The peer review history for this paper can be accessed here: http://sciencedomain.org/review-history/19271 